\author{
ROBERTO L. MAYER
}

\title{
Los dos álbumes de Pedro Gualdi
}

$\mathrm{P}$ ARA EL AÑo de I84I ya se habían publicado varios álbumes con ilustraciones de México. En I8Io se publicó en París Vue des cordilleres, de Aleen 1829, su álbum Six Views of the Most Important Towns and Mining Districts, Upon the Table Land of Mexico, con seis aguafuertes que muestran diversas poblaciones mineras de México; un año antes, la señora Ward había ilustrado con litografías el libro Mexico in I827, escrito por su marido. Carl Nebel publicó en París en 1834, y años después reeditó con portada en español, su Voyage pintoresque et archeologique dans la partie la plus interesante du Mexique, con cincuenta vistas de la ciudad de México, algunas ciudades de provincia y motivos arqueológicos. En Londres, en I840, Daniel Thomas Egerton publicó su inigualable carpeta Views in Mexico, con doce litografías acuareladas.

Con todo, Pedro Gualdi en I841 tuvo el mérito de ser el primero en imprimir y publicar un álbum en México, dándole el título de Monumentos de Méjico. Es notable la belleza de este álbum, muy conocido y admirado por bibliófilos y coleccionistas de estampas mexicanas antiguas y muy difundido en ediciones facsimilares.

Vamos a hablar aquí de un hecho que aparentemente no ha sido observado hasta ahora: la existencia de dos ediciones diferentes de este notable álbum, y a describir las características que tienen en común y las diferencias que los distinguen. A priori, vamos a hablar de "primera" y "segunda" ediciones, lo cual se justificará durante el desarrollo del presente estudio.

Las dimensiones de las litografías son similares en ambas ediciones, variando entre 247 y $257 \mathrm{~mm}$ de altura por 373 a $394 \mathrm{~mm}$ de ancho. En ambas ediciones, la encuadernación es a la italiana. 


\section{Diferencias y semejanzas en las ediciones}

Las portadas de las dos ediciones son aparentemente iguales, llevan el mismo marco y adornos, y el texto en general es el mismo; ambas portadas dicen "Año I84I". Sin embargo, hay diferencias importantes. La primera edición lleva la leyenda "Obsequio a los señores abonados", y en la segunda edición fue reemplazada por "Se vende en casa de los Editores".

Los medallones con los títulos de las vistas contenidas en cada álbum diferen como sigue:

\section{Primera edición}

MEDALLÓN IZQUTERDO

Catedral.

Plaza de Santo Domingo y Aduana.

Exterior de $\mathrm{N}^{\mathrm{a}} \mathrm{S}^{\mathrm{a}}$ de Guadalupe.

Interior de la Universidad.

Interior de Minería.

Colegio de Minería.
MEDALIÓN DERECHO

Interior de Catedral.

Santuario de $\mathrm{N}^{\mathrm{a}} \mathrm{S}^{\mathrm{a}}$ de Guadalupe

Paseo de la Independencia.

Patio del Convento de $\mathrm{N}^{\mathrm{a}} \mathrm{S}^{\mathrm{a}}$ de la Merced.

Cámara de Diputados.

Casa Municipal.

Segunda edición

MEDALIÓN IZQUIERDO

Catedral.

Plaza de Santo Domingo y Aduana.

Interior de la Universidad.

Interior de $\mathrm{N}^{\mathrm{a}} \mathrm{S}^{\mathrm{a}}$ de Guadalupe. *

Interior de Minería.

Collegio de Minería
MEDALLÓN DERECHO

Interior de Catedral.

Interior de la Alameda.

Paseo de la Independencia.

Patio del Convento de $N^{a} S^{a}$ de la Merced.

Cámara de Diputados.

Casa Municipal.

* Aquí hay un enror ya que la vista es del exterior del Santuario de $N^{a} S^{a}$ de Guadalupe.

A diferencia de la primera edición, en la segunda cada estampa viene acompañada con un texto descriptivo. Peto la diferencia fundamental entre las dos ediciones del álbum de Gualdi la encontramos en las estampas mismas, pues muchas de ellas son diferentes aun cuando llevan el mismo título.

Así tenemos que la vista denominada Catedral de Méjico difiere en las dos ediciones en que en la primera el ángulo es tal que incluye una esquina del Parián, mientras que en la segunda se ve a lo largo de la calle del Empedradi- 
Ilo (hoy Monte de Piedad). Las vistas denominadas Interior de la catedral son totalmente diferentes: la primera edición muestra el altar del Perdón mientras que la segunda retrata el coro.

Las vistas denominadas Santuario de N.S. de Guadalupe difieren en que en la primera edición la vista está tomada desde el sureste, quedando la capilla del cerro del Tepeyac al lado derecho de la estampa, mientras que en la segunda edición la vista del santuario está tomada desde el suroeste, quedando dicha capilla al lado izquierdo. La vista denominada Interior del santuario de N.S de Guadalupe se eliminó en la segunda edición y en su lugat apareció la llamada Alameda de Méjico.

Ambas ediciones contienen una vista denominada Colegio de Minería. Sin embargo, las dos vistas del espléndido edificio neoclásico de Tolsá son diferentes: en la primera edición, la vista está tomada desde el noreste, es decir, hacia la Alameda - incluso se distingue a la distancia el acueducto de $\mathrm{La}$ Mariscala-, mientras que en la segunda edición la vista es desde el noroeste, hacia la catedral. Asimismo, las dos vistas que llevan por nombre Interior del Colegio de Minería son totalmente diferentes entre sí: en la de la primera edición aparece el patio, mientras que la de la segunda es una vista de la escalinata monumental.

Las vistas denominadas Casa municipal son iguales en cuanto al punto de vista, pero difieren en los elementos que les dan vida, como nubes, personajes, un carruaje y un jinete que aparecen en la segunda edición y no en la primera, y en varios detalles menores. Más notable que las diferencias entre estas dos vistas es el hecho de que Gualdi haya logrado dibujar, en dos piedras litográficas, una repetición tan exacta del mismo tema arquitectónico.

Este comentario es válido también para las dos vistas que llevan como nombre Interior de la Universidad de Méjico. En la primera edición hay un canónigo, en la segunda no, y en ambas hay un perro, pero en diferente lugar.

Se observa una ligera diferencia de textura entre las estampas de cada edición, debida a las características propias de las piedras empleadas.

Pedro Gualdi no eta consistente en cuanto a firmar y fechar sus obras: de hecho, no todas las litografías están firmadas y sólo dos de la primera y una de la segunda ediciones llevan fecha, I840 en la primeta, i842 en la segunda. Casi todas las estampas llevan en la parte inferior una indicación de que Pedro Gualdi era el litógrafo.

Curiosamente, dos obras de la segunda edición, La catedral de Méjico e Interior de la catedral, dicen "Pintor y litógrafo", lo cual confirma que en ese 
tiempo Gualdi estaba pintando las mismas vistas. Con frecuencia, Gualdi hizo versiones al óleo de sus litografías, o viceversa. Uno de los misterios que rodean a Gualdi es precisamente saber si hacía litografías basándose en sus óleos o si le eran encargados óleos por gustar sus litografías. Es probable que se dieran ambas circunstancias.

En el cuadro I se resumen los nombres de las diversas vistas, las principales características que las distinguen, el nombre del taller donde se imprimieron, según la nota al calce de cada litografía, y se indica si están firmadas y fechadas.

De la comparación de las estampas se desprende que sólo cuatto de las doce vistas, Plaza de Sto. Domingo y Aduana, Claustro del convento de $\mathrm{Na}$. Sa. de la Merced, Paseo de la independencia y Camara de los diputados, son comunes en ambas ediciones $y$, por ende, fueron impresas con la misma piedra y en el mismo taller.

Es interesante observar que las cuatro estampas comunes en ambas ediciones, lo mismo que la portada, son del taller "Imprenta Lito de Masse y Decaen, Sa. Clara No. 8" y, por otra parte, que todas las estampas de la segunda edición también se imprimieron en ese taller. Las demás estampas de la primera edición se publicaron en tres talleres diferentes: en "Lito. Junto al Correo", establecimiento de Julio Michaud y Thomas, Interior de la catedral, Colegio de Minería y Casa municipal; en "Lito. Calle S. Francisco No. I5", taller de J.A. Decaen en 1839 , Catedral de Méjico, Santuario de N.S. de Guadalupe e Interior del santuario de N.S. de Guadalupe, y en "Lito. frente al Correo No. 5", taller de Hipólito Salazar en 1840, Interior de la Universidad de Méjico.

\section{La obra de Gualdi}

Se sabe muy poco de la vida de Pedro Gualdi. Llegó a México hacia 1835 con una compañía italiana de ópera, como pintor de escenogtafía, y permaneció en México unos quince años. No hay información precisa de su labor antes de I84I, aunque existen algunas litografías sin firma que tienen toda la apariencia de haber sido obra de su mano; entre ellas, podemos mencionar Convento de San Agustin En la memorable jornada del Is al 27 de Julio de I840, "Julio Michaud, editor, almacén de estampas junto al correo"; Encuentro en la garita de San Lazaro. El día 20 de Julio de 1840, "Julio Michaud, editor, almacen de 
estampas junto al correo" y Vista del Palacio Nacional de Mejico despues de la memorable jornada del 15 al 27 de julio de 1840 " "Lito. Callejon S. Clara No. 8".

También existen vistas posteriores, que también pueden ser de él, o de algún alumno suyo, como la litografía con el título Vista interior del Palacio Nacional de Mejico. Ocupado por los Federalistas, "se vende Ia. calle del Relox no. 2.", de un suceso de I845. Todas estas vistas tienen la apariencia de haber sido hechas para ser vendidas sueltas.

De las obras mencionadas es de interés Convento de San Agustín..., ya que Gualdi hizo sus vistas panorámicas de la ciudad de México desde la torre sur de la iglesia. El mismo lugar fue aprovechado por muchos otros pintores, dibujantes y fotógrafos, para sus propias vistas panorámicas, hasta que la torre fue derruida en 1884, al transformatse el templo en la Biblioteca Nacional.

Sabemos que Gualdi colaboró en los tomos v y vi de El Mosaico Mexicano, ya que aparece su firma en litografías de pequeño formato del Palacio de Minería. La vista exterior es réplica de la que apareció en la primera edición de su álbum y fue impresa en la "Lito. Almacén de estampas junto al Correo"; la del interior es téplica de la escalinata que aparece en la segunda edición del álbum y fue impresa en la "Lito. de Masse y Decaén". En la misma revista hay otras litografías, sin firma, que tienen todo el estilo de Gualdi, Colegio de Guadalupe de Zacatecas y otras, generalmente de la "Imp. Lito callejon de S. Clara No. 8", o sea Masse y Decaen.

En el Almacén Univeral, impreso en el taller de Miguel González en I840, aparece una vista titulada Plazuela de santo Domingo (Méjico), sin firma, a su vez impresa en "lito Almacén de estampas junto al Correo", que evidentemente es precursora de la que Gualdi incluyó en su álbum. Es muy probable que también sean de Gualdi las otras estampas que aparecen en la misma obra y que tampoco llevan firma.

En el librillo Carta dirigida al excmo sr. presidente.... de José María Gutiérrez de Estrada, impreso por Ignacio Cumplido en 1840, aparece una Vista del Palacio Nacional de Méjico después de la lamentable jornada del Is al 27 de Julio 1840 , firmada por Gualdi, impresa en pequeño formato ( $10 \times 13 \mathrm{~cm}$ ) en "Lito callejón Betlemitas No ir".

De todo lo arriba anotado se desprende que Gualdi estuvo relacionado con los siguientes talleres litográficos: "Julio Michaud editor almacén de estampas junto al correo", "Lito. Calle S. Francisco No I5", "Lito frente al Correo No 5" e "Imprenta Lito de Masse y Decaen, Sa Clara No 8". No podemos descartar que hubiera trabajado también en otros talleres. 


\section{Copia y reproducción de las litografias}

El hecho de que, con una sola excepción, la firma de Gualdi esté sólo en aquellas estampas que se publicaron en su propia obra, nos lleva a pensar que al recibir paga como artesano, no estaba autorizado para firmar su obra litográfica. Fue a partir de I84I cuando publicó a sus propias expensas, como nos dice en el breve párrafo al reverso de la portada de la primera edición de su álbum, que aparece su firma en forma más regular en sus litografías. El texto dice así:

Acogiéndose el autor á los principios y leyes que en todos los Países cultos protegen la propiedad, y considerando que la tiene en esta colección de Vistas formada e inventada por el solo y a solas sus espensas; protesta perseguir en juicio cualquier nueva edición y falsificación que se hiciere.

Mejico Enero 9 de 1841 Pedto Gualdi

La fecha y la firma son autógrafas. Hay que hacer notar que la segunda edición no contiene esta leyenda.

Así que los óleos y litografías de Gualdi publicados a partir de I84I normalmente llevan su firma; decimos "normalmente", pues observamos ocasiones en que sólo firmaba uno de los cuadros de una serie, como en el caso del cuarteto de óleos panorámicos de la ciudad de México, dos de los cuales están en el Museo Franz Mayer, sin firma, y el tercero en una colección particular, con firma; el paradero del cuarto es aún desconocido. Es un hecho que el grupo de óleos panorámicos de la ciudad de México constaba de cuatro piezas porque se conocen las litografías correspondientes.

La advertencia que Gualdi colocó al reverso de la portada de la primera edición de su álbum, transcrita arriba, nos demuestra el temor que tenía Gualdi de que su obra fuera "pirateada". Seguramente vio copiar obras litográficas de otros autores en los talleres donde prestaba sus servicios.

De Julio Michaud y Thomas, editor y dueño de estampería, sabemos poco, peto una de sus direcciones era "frente al Correo", donde se imprimió una de las litografías de la primera edición del álbum de Gualdi. Evidentemente, Gualdi trató de protegerse de éste y de otros editores, pero no lo logró. Fue precisamente Michaud y Thomas quien publicó copias de casi todas las vistas creadas por Gualdi, mal dibujadas, firmadas por Urbano 
López, en el Álbum pintoresco de la República Mexicana, la mayoría de cuyas estampas mandó imprimir en París.

Al no llevar fecha la portada del álbum de Michaud, pensamos que se iba armando con un contenido variable, conforme se vendía. Tenemos a la mano un ejemplar de este álbum y pensamos que data de alrededor de 1848 , por contener escenas de la guerra de intervención estadounidense. Gualdi todavía estaba en México cuando salió a la venta el mencionado álbum y, seguramente, se vio impotente para lograr que Michaud y Thomas desistiera de su descarada copia.

John Phillips y Alfred Rider copiaron vistas de la primera edición del álbum de Gualdi para su propio libro, Mexico Illustrated: Interior de la catedral (el altar del Perdón), Claustro del convento de Na Sa de la Merced (reduciendo el largo de la iglesia) y Plaza de Sto. Domingo y Aduana; la vista Paseo de la independencia la copiaron parcialmente. Rider transformó todas estas vistas en escenas costumbristas agregando un gran númeto de personajes.

\section{Las dos ediciones}

La portada de la primera edición del álbum de Gualdi trae la leyenda "obsequio a los señores abonados". Hay que entender que el obsequio se limitaba a la hoja de dicha portada. Era costumbre común en el siglo xIx publicar libros bajo el sistema de entregas, reuniendo anticipadamente el número suficiente de abonados para asegurar el éxito económico o por lo menos cubrir los gastos editoriales. En este caso, Gualdi vendió una colección de doce láminas y, al término de su compromiso, le obsequió a cada suscriptor la portada a fin de que pudiera encuadernar su colección como una obra completa.

Sólo una de las vistas, Interior del santuario de N.S. de Guadalupe está fechada - en I840-, lo cual nos confirma la fecha de publicación de la obra. Al pie de la misma litografía aparece la leyenda "Se vende en la casa del Autor Calle Donceles No. 2", lo que a su vez nos informa de su domicilio y nos confirma el hecho de que Gualdi en persona vendió las vistas de su primer álbum.

La poca frecuencia con que se encuentra la primera edición del álbum de Gualdi se explica por el número de abonados, seguramente reducido, y por la desidia de la gente para encuadernar su colección; en el comercio de es- 
tampas antiguas se ven ocasionalmente vistas sueltas de esta edición, por lo que se ha pensado que se trataba de estampas que se vendieron sueltas. La segunda edición es un poco más conocida y es la que se ha reproducido en varias ediciones facsimilares.

$\mathrm{Al}$ existir demanda para un número adicional de álbumes, Gualdi debe haber tenido alguna dificultad para lograt la impresión en los diferentes talleres donde se hicieron las primeras litografías o para que le entregaran las piedras en que se habían hecho; tal vez no previó necesitar un mayor número de ejemplares y las planchas ya habían sido borradas. Al imprimir las estampas en su taller, Masse y Decaen podía ofrecerle a Gualdi financiamiento y un mejor éxito comercial. El hecho es que Gualdi tuvo que dibujar nuevamente ocho de sus vistas sobre piedras nuevas, con diferencias más o menos importantes y haciendo cambios, ya sea por su propio gusto o por compromisos con los talleres donde había hecho el trabajo antes.

Sabemos que la primera edición del álbum se terminó con la entrega de la portada que lleva la fecha manuscrita " 9 de enero de $184 \mathrm{I}$ ". La segunda edición lleva una portada con poca variación y con el mismo año, pero contiene una lámina fechada en I842; este dato nos confitma la existencia de la segunda edición, sin precisar la fecha de su publicación.

\section{Aspectos artísticos}

No se puede concluir un estudio de los álbumes de Gualdi sin hacer notar su gran calidad técnica y artística. Las portadas de los álbumes son un alarde de dibujo, caligrafia, claroscuro, paisaje y lo que suele llamarse tromp l'ail: algunas partes del dibujo adquieten terceta dimensión, parecen salirse del papel. El paisaje urbano es técnicamente exacto, el detalle de las ilustraciones las convierte en verdaderos documentos; no sorprende pues que, hace algunos años, la estampa Camara de diputados sirviera para restaurar ese recinto a la condición que guardaba en 1840 , dándosele el crédito correspondiente a Gualdi al haberse colocado ahí un ejemplar de ella.

Los edificios, calles y plazas que dibuja Gualdi adquieren plasticidad, no sólo por la propia sombra que proyectan, sino también por las sombras de las nubes. Las distancias se hacen palpables por la difuminación en el dibujo, los segundos y tercetos planos se hacen cada vez más suaves haciéndonos sentir su lejanía. Sin embargo, los personajes de Gualdi son rígidos y carecen de 
vida. Hay que subrayar que el mismo Gualdi, en las portadas de sus álbumes, se calificaba como "Pintor de Perspectiva", oficio que innegablemente cumplió a la perfección.

Uno de los méritos de Gualdi es haber transmitido sus conocimientos de litografía, sombra y perspectiva a varios jóvenes talentosos, compañeros de trabajo, entre ellos a Casimiro Castro; en el caso de este último, el alumno logró un dibujo menos rígido, más suave, más amable y con personajes más reales. Es un caso de alumno que superó al maestro.

\section{Conclusión}

Es posible afirmar, en fin, que existen dos ediciones diferentes del álbum Monumentos de Méjico de Pedro Gualdi, la primera publicada por entregas, llevando la última de ellas fecha 9 de enero de 1841; la segunda edición fue publicada en 1842. o después. Las dos ediciones tienen cuatro vistas idénticas y ocho diferentes. De las ocho vistas diferentes, siete tienen temas de nombre similar, pero con encuadres diferentes, y una más es de tema totalmente distinta.

La primera edición la costeó el autor, obteniendo para ello suscripciones de abonados, vendiendo hojas sueltas en su propio domicilio y haciendo la impresión en diversos talleres. La segunda edición se imprimió en un solo taller y cada lámina se acompañó de un texto descriptivo. Los ejemplares de ambas ediciones del álbum son raros, siéndolo aún más los de la primera edición : 


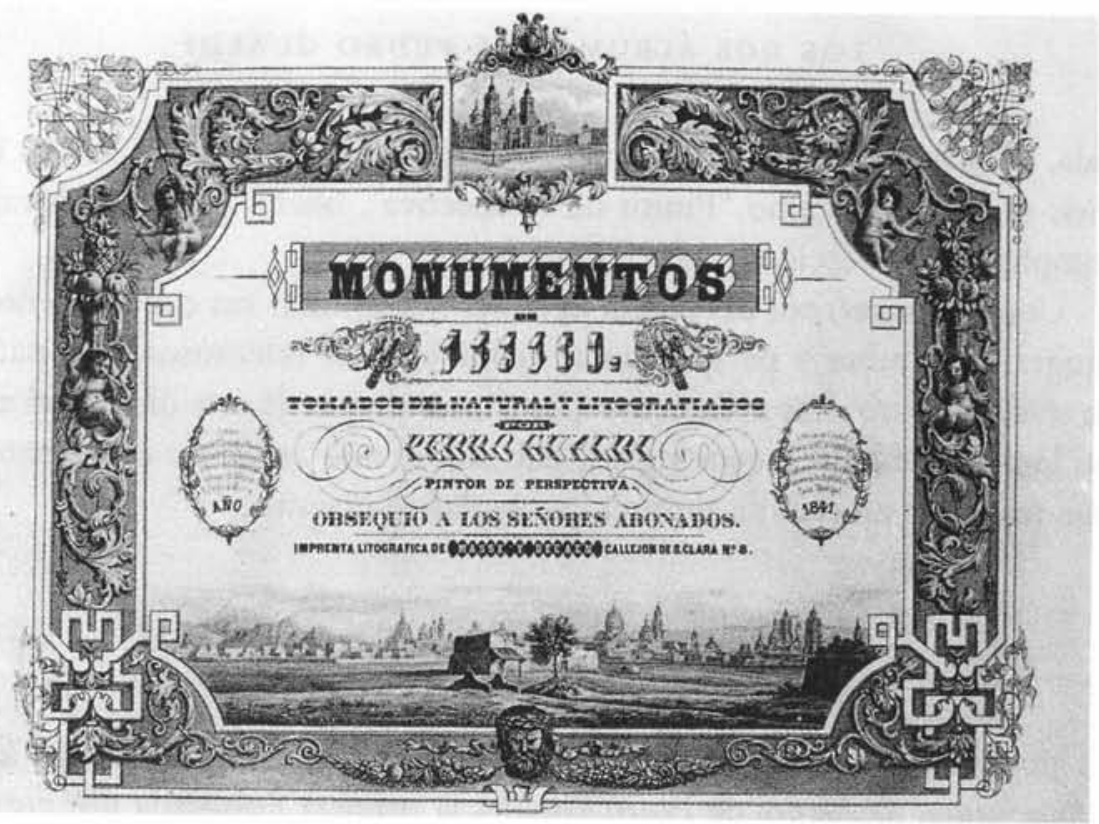

Figura I. Portada del portafolio Monumentos de México (I841). Foto: Roberto L. Mayer (en adelante R.L.M).

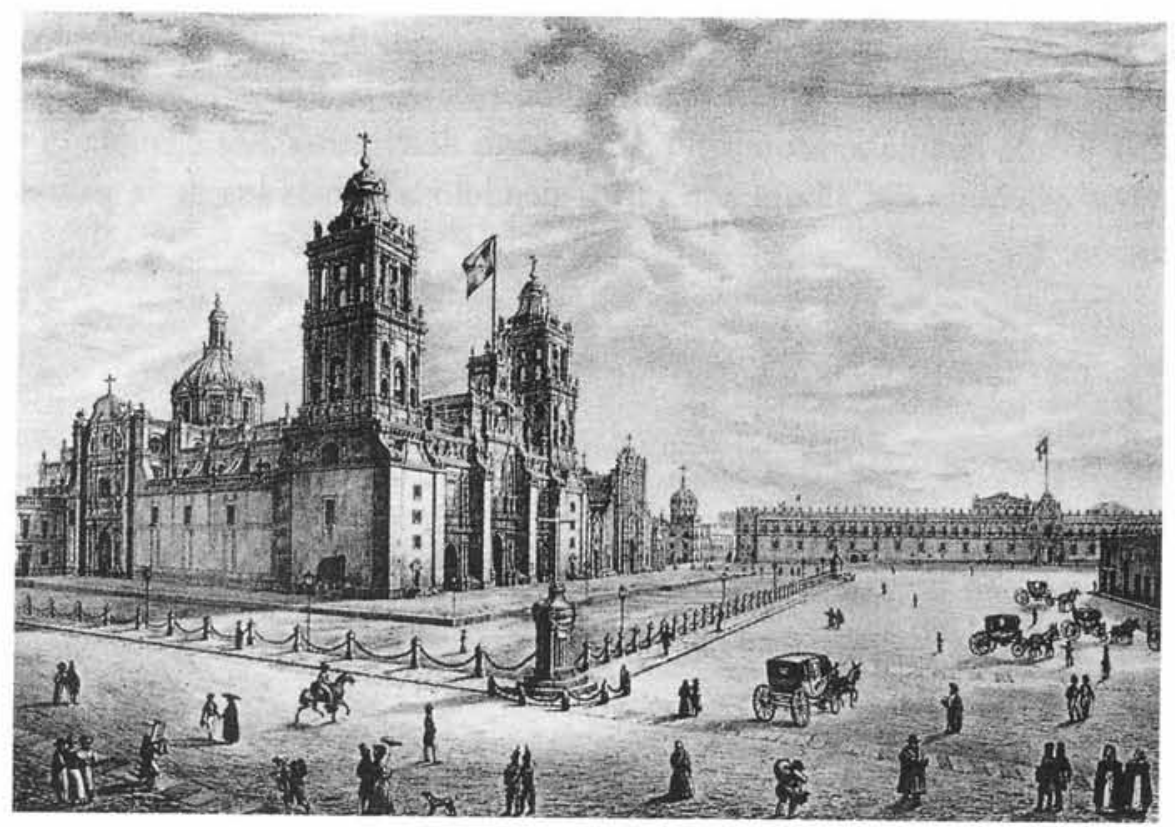

Figura 3. Pedro Gualdi, Catedral de Méjico, 184r. Foto: R.L.M. 


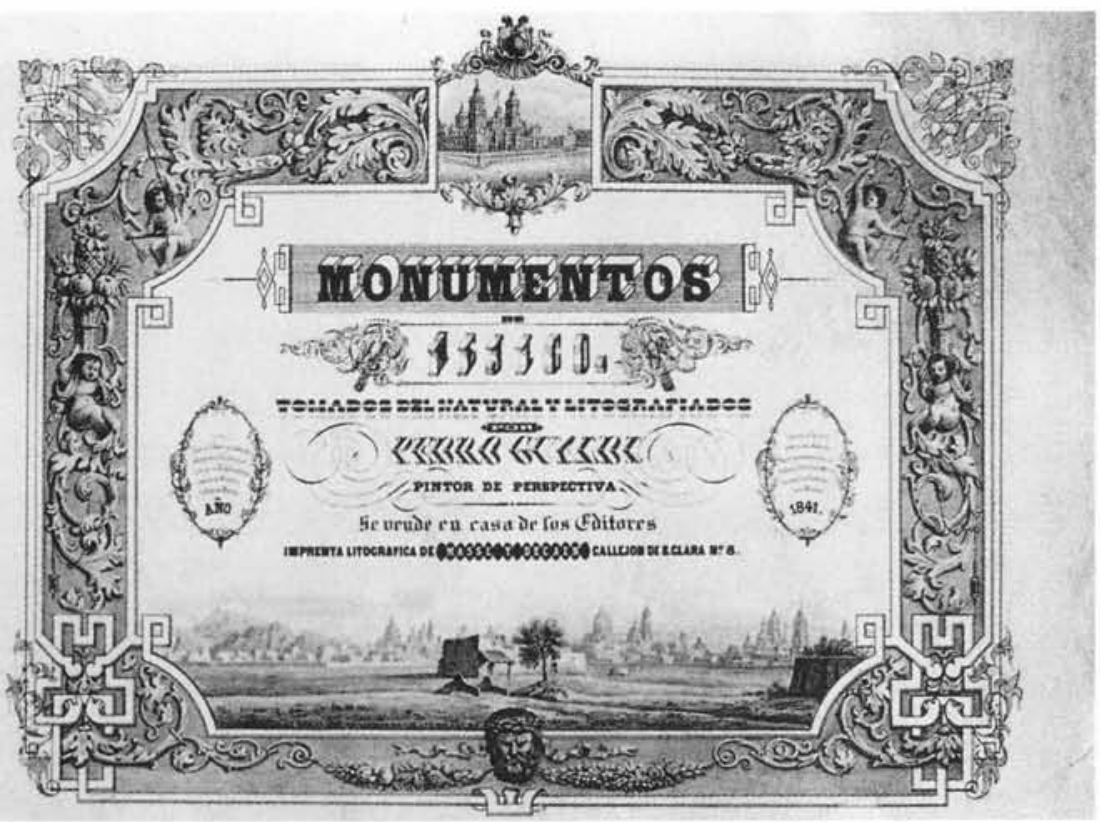

Figura 2. Portada del libro Monumentos de México (I84I). Foto: R.L.M.

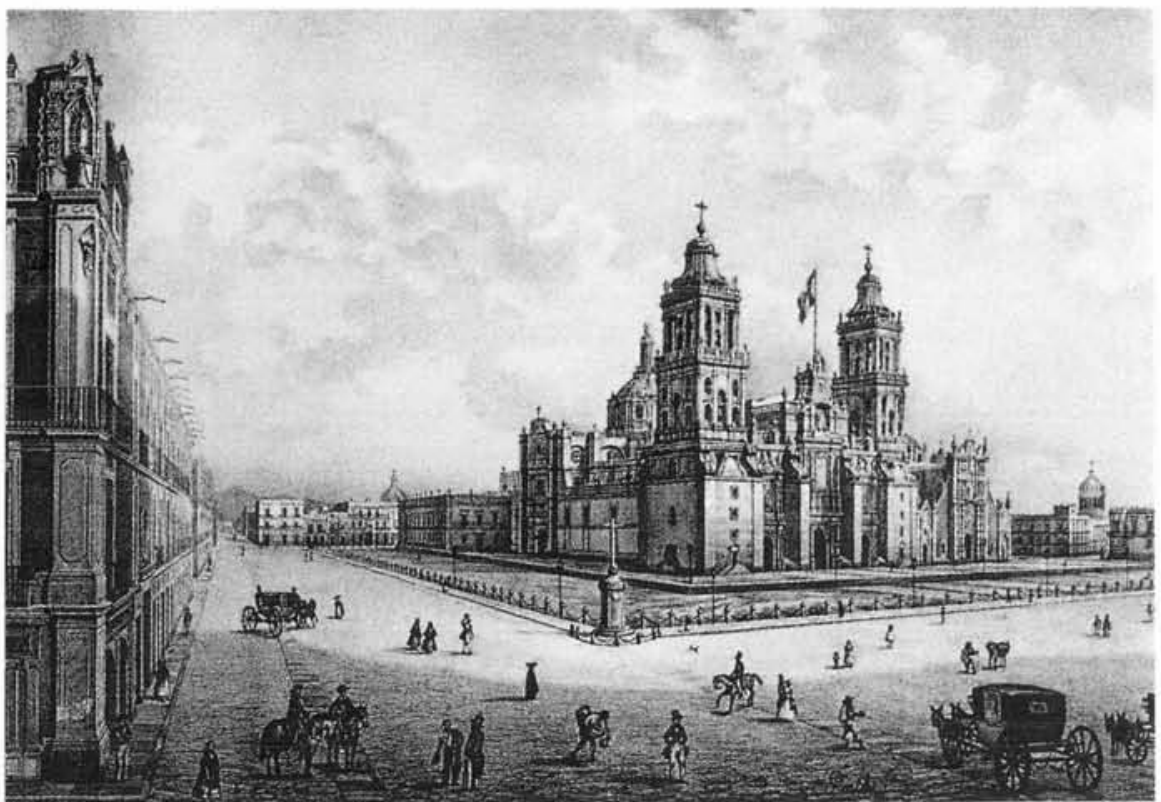

Figura 4. Pedro Gualdi, Catedral de Méjico, 184I. Foto: R.L.M. 


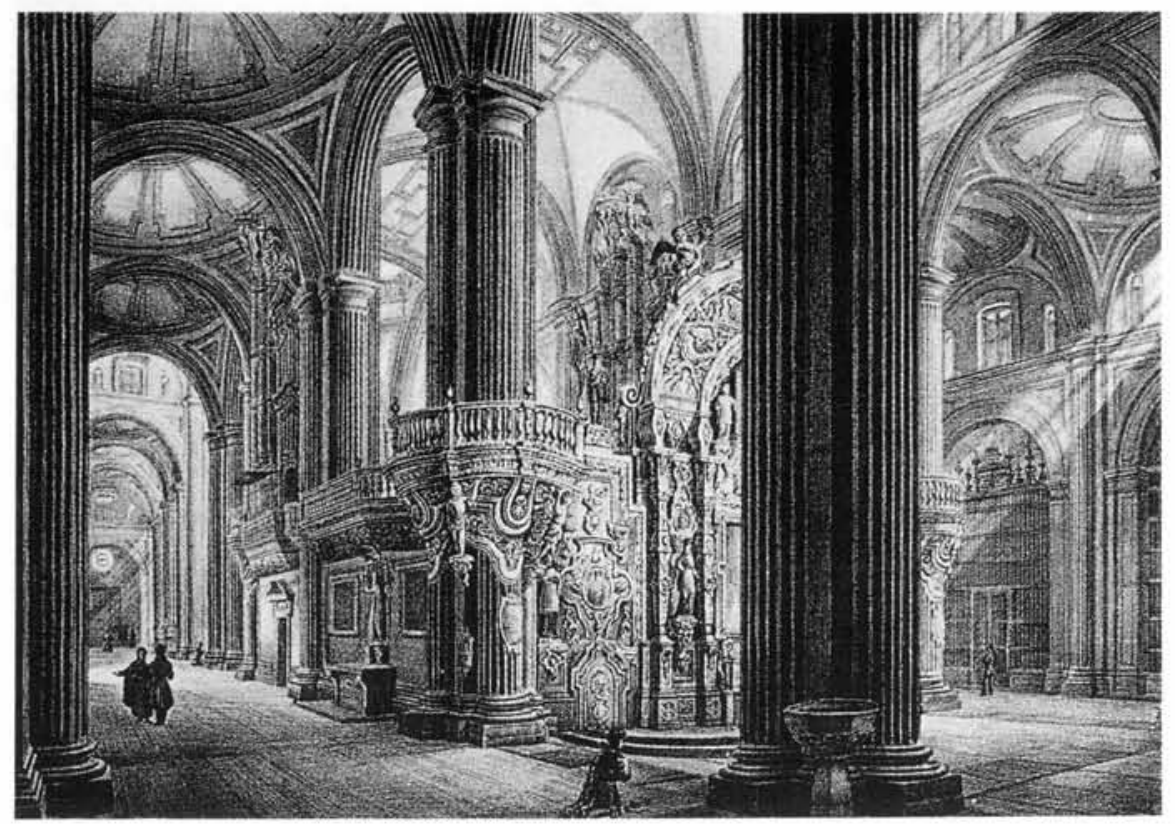

Figura 5. Pedro Gualdi, Interior de la catedral, 1841. Foto: R.L.M.

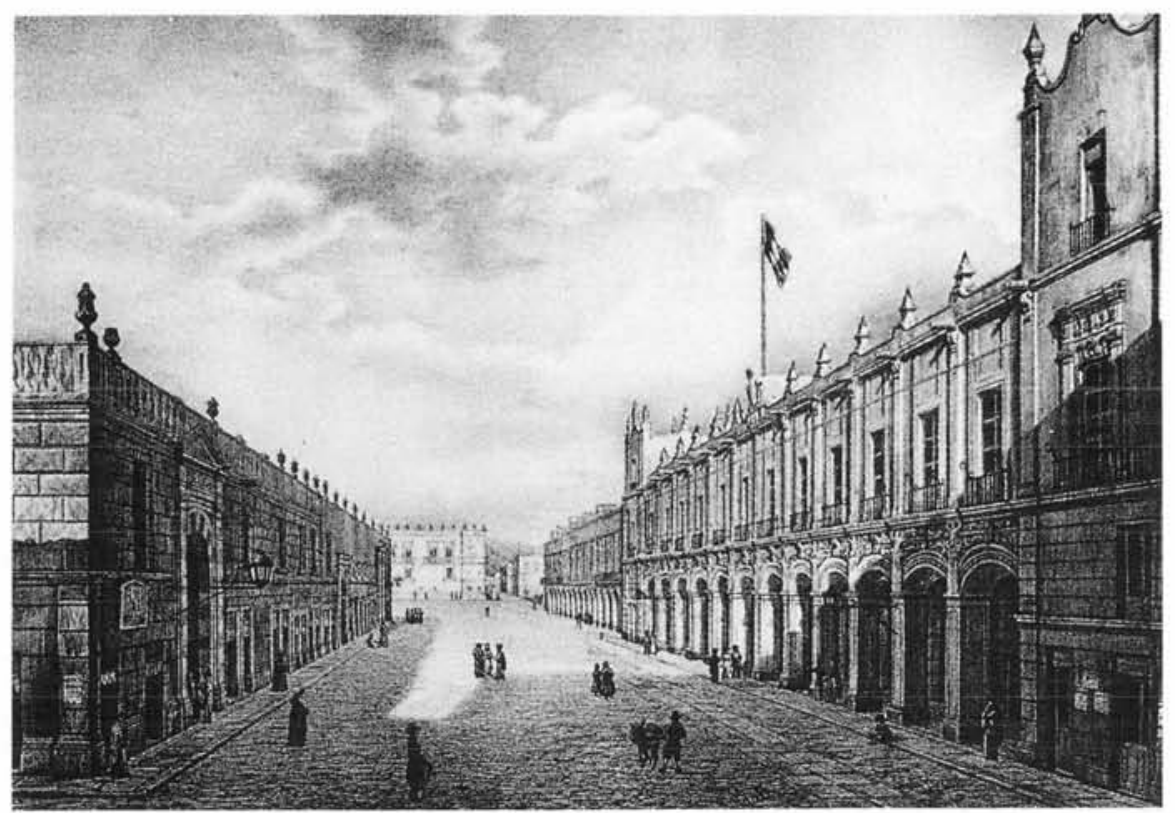

Figura 7. Pedro Gualdi, Casa municipal, 1841. Foto: R.L.M. 


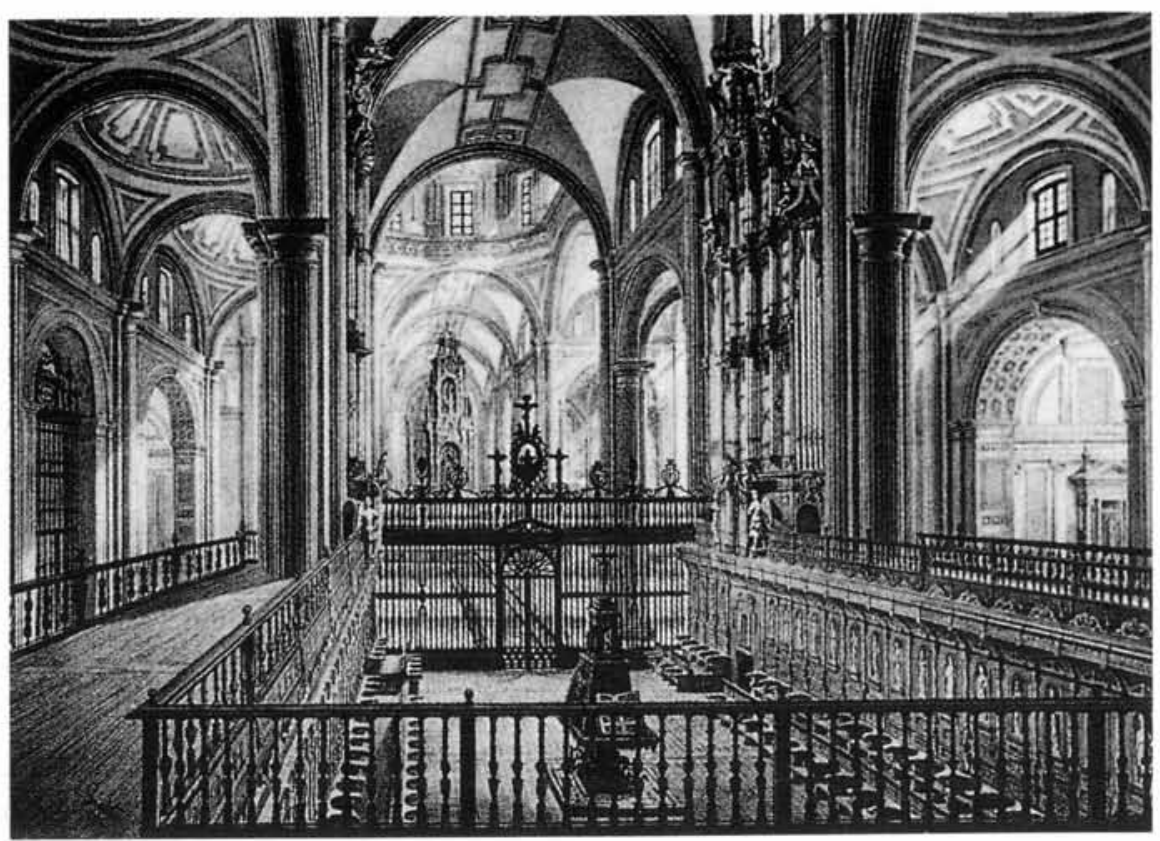

Figura 6. Pedro Gualdi, Interior de la catedral de Méjico, i841. Foto: R.L.M.

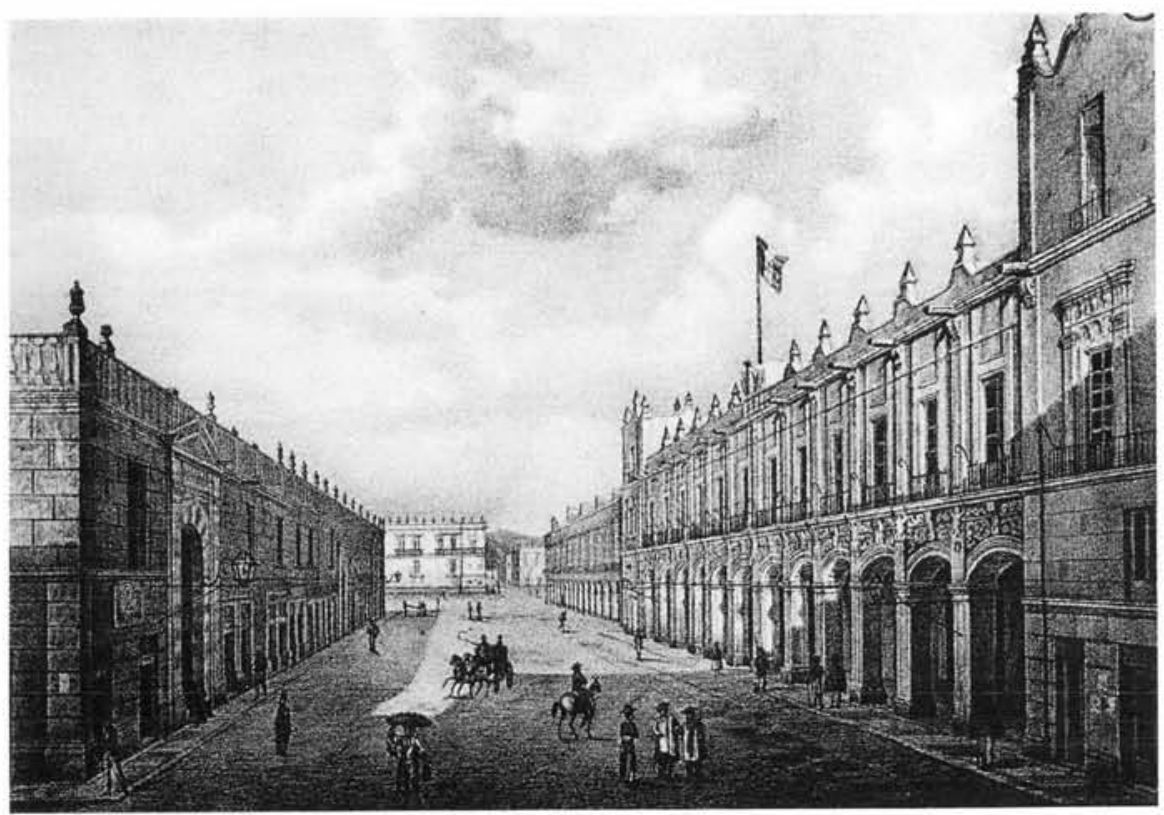

Figura 8. Pedro Gualdi, Casa municipal, 184I. Foto: R.L.M. 


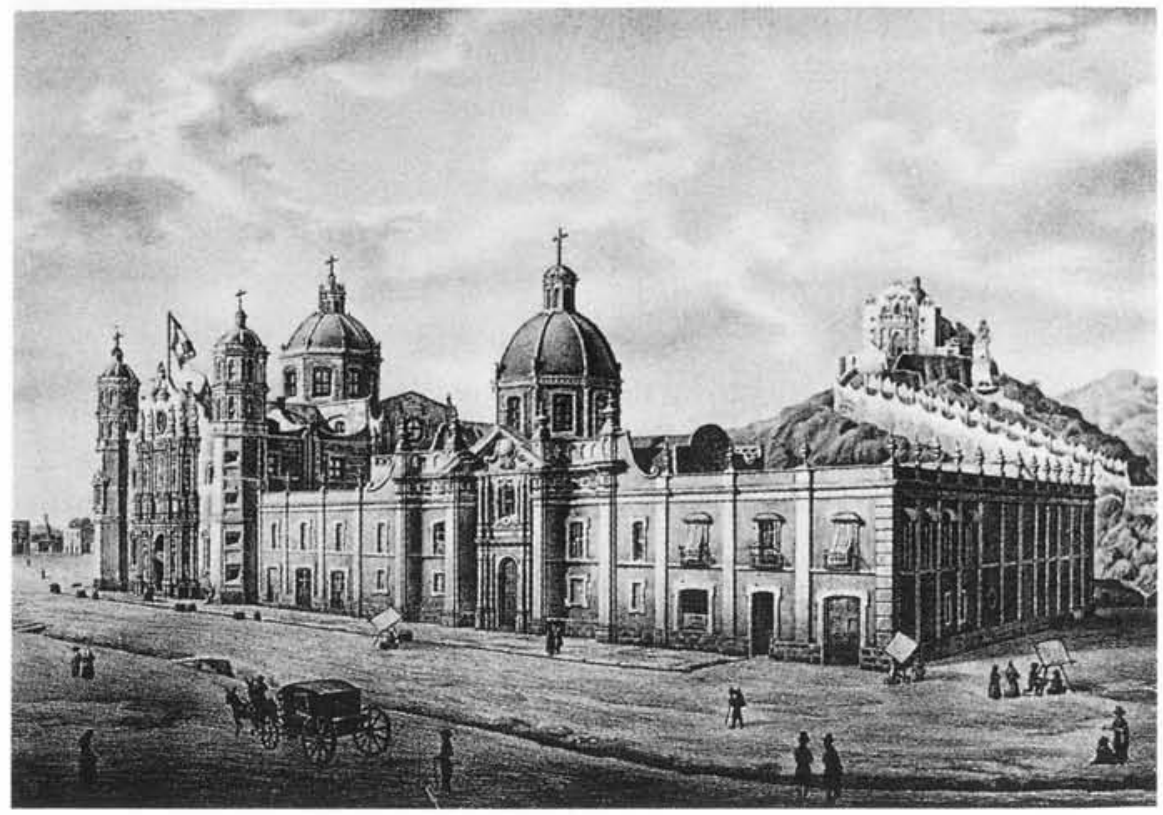

Figura 9. Pedro Gualdi, Santuario de N.S. de Guadalupe, 1841. Foto: R.L.M.

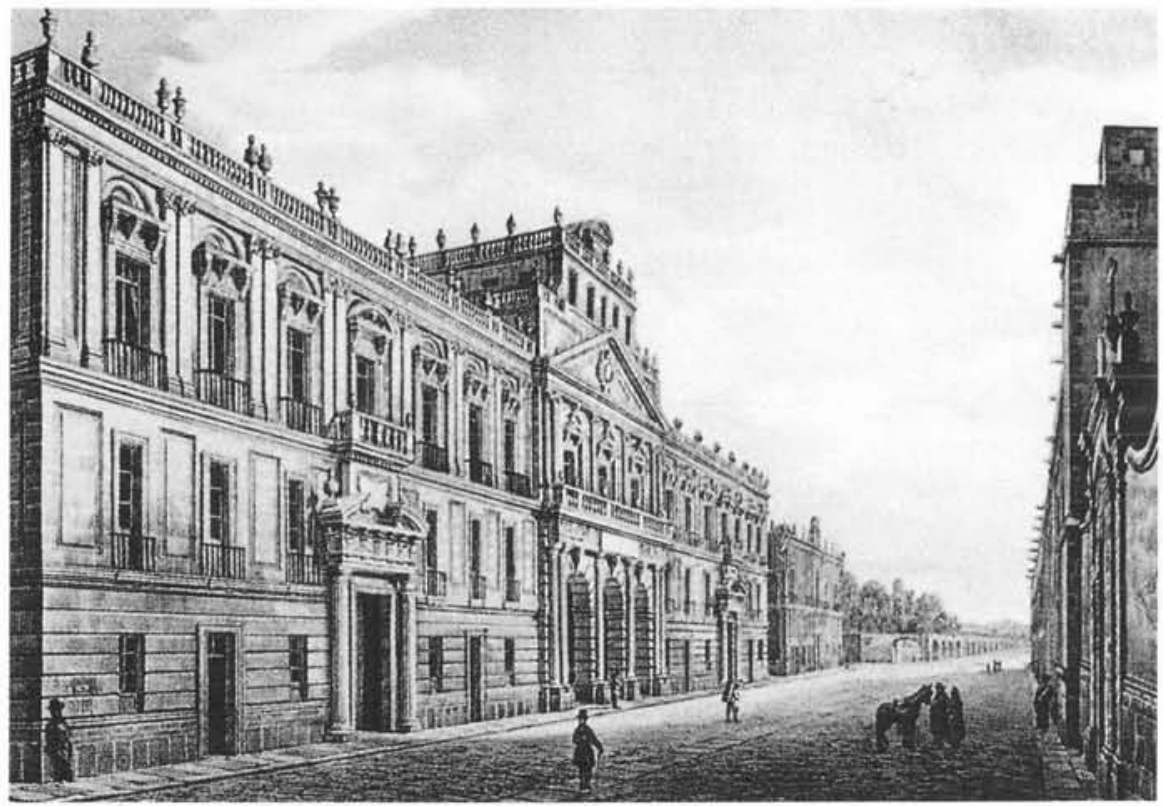

Figura Ir. Pedro Gualdi, Colegio de Mineria, I84r. Foto: R.L.M. 


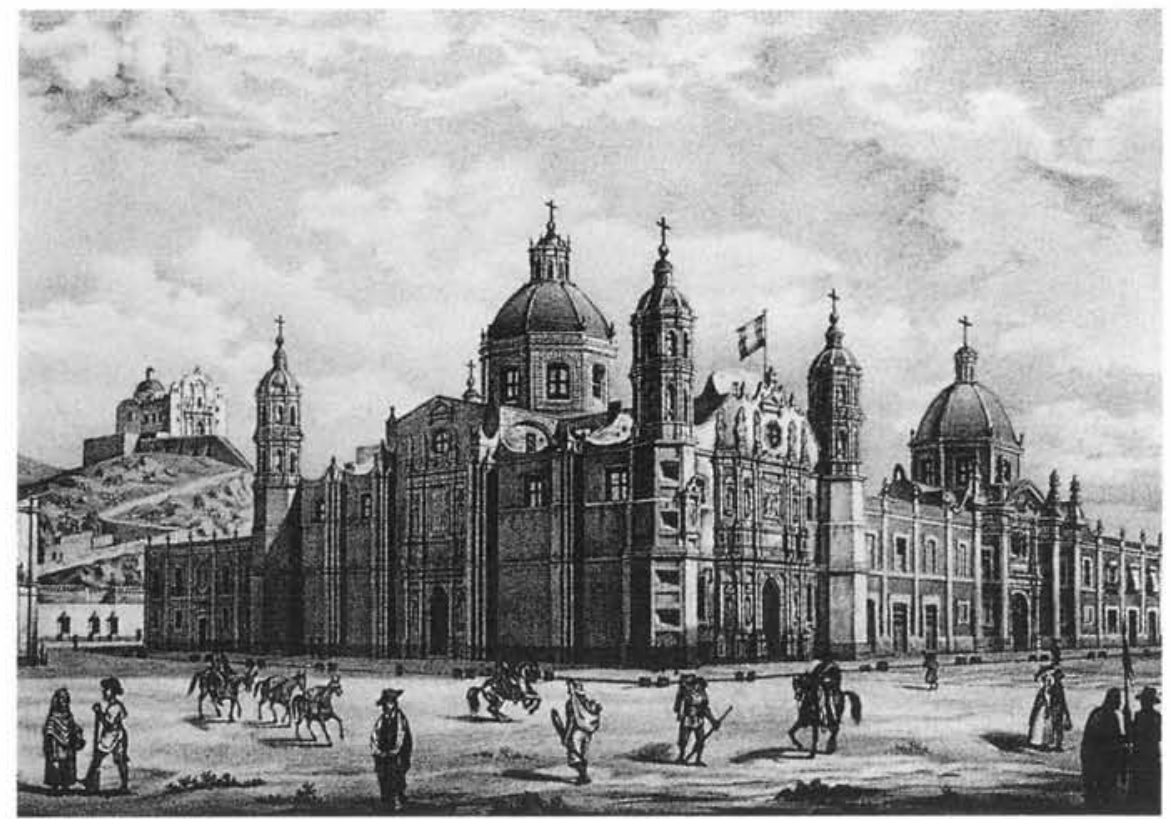

Figura io. Pedro Gualdi, Santuario de N.S. de Guadalupe, 184I. Foto: R.L.M.

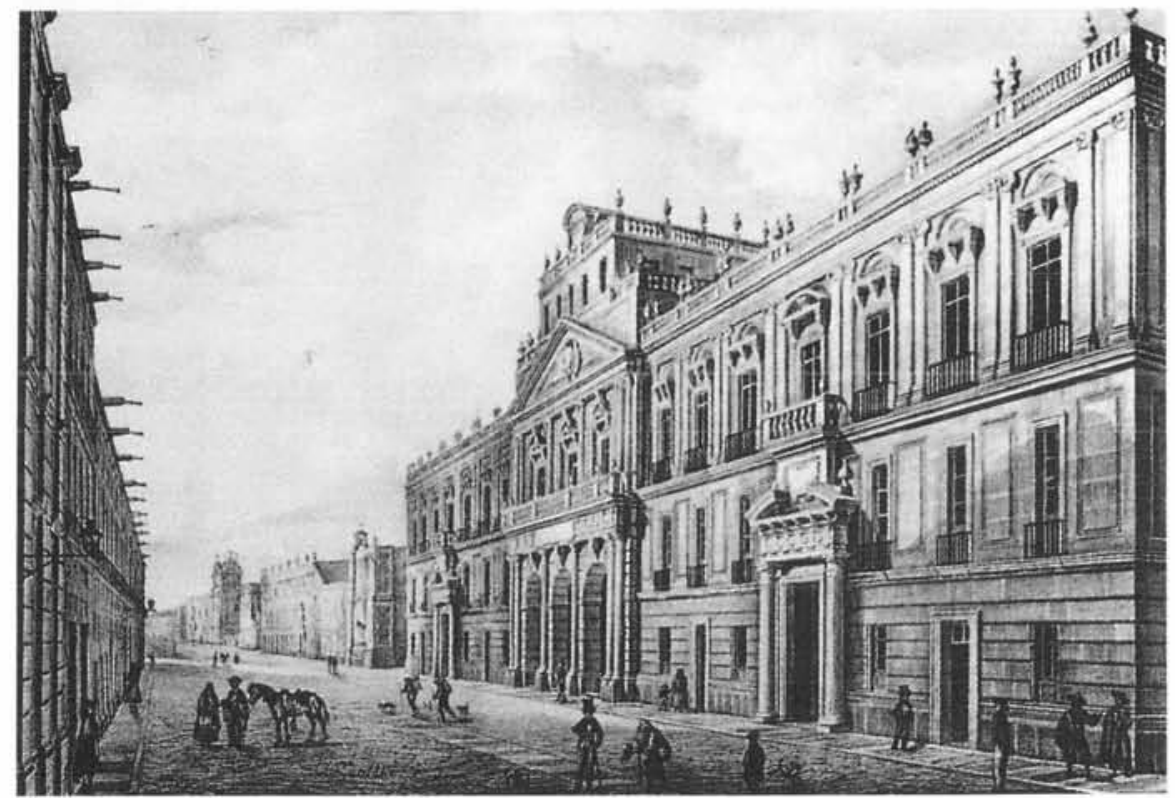

Figura I2. Pedro Gualdi, Colegio de Minería, I84I. Foto: R.L.M. 
DOI: http://dx.doi.org/10.22201/iie.18703062e.1996.69.1772

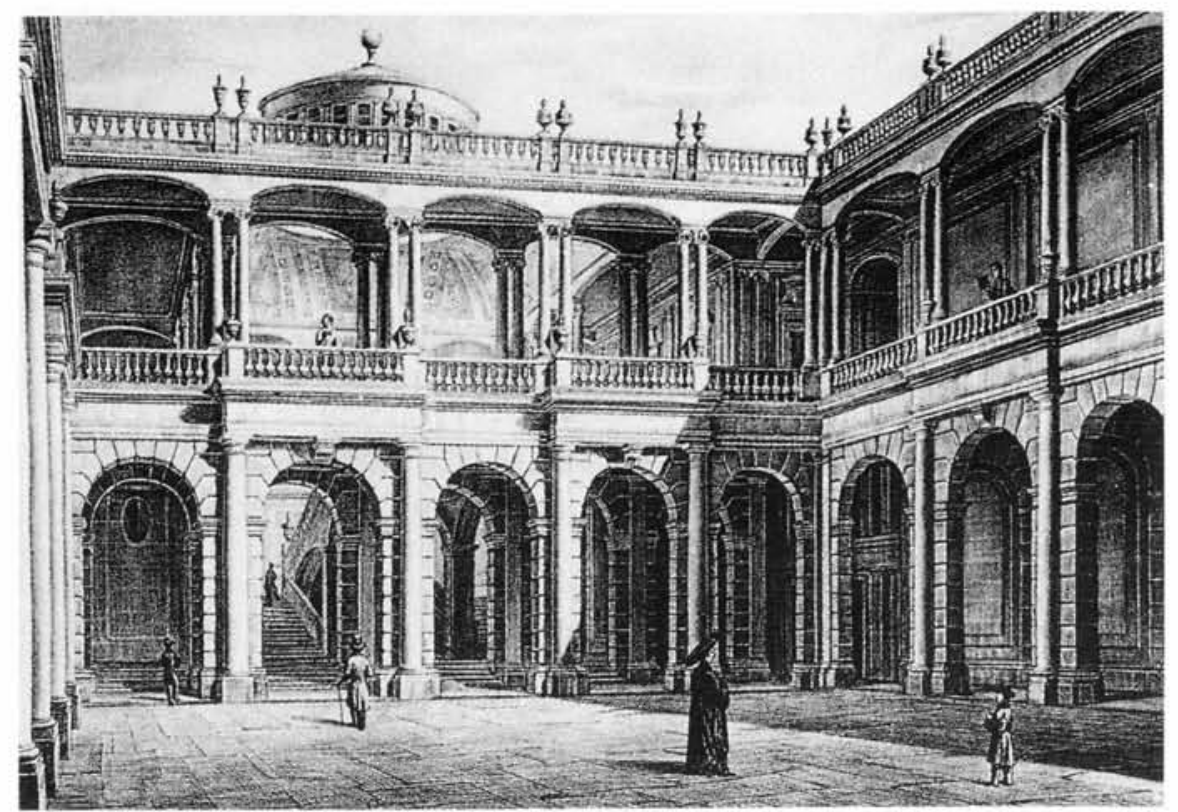

Figura 13. Pedro Gualdi, Interior del Colegio de Minería, I84I. Foto: R.L.M.

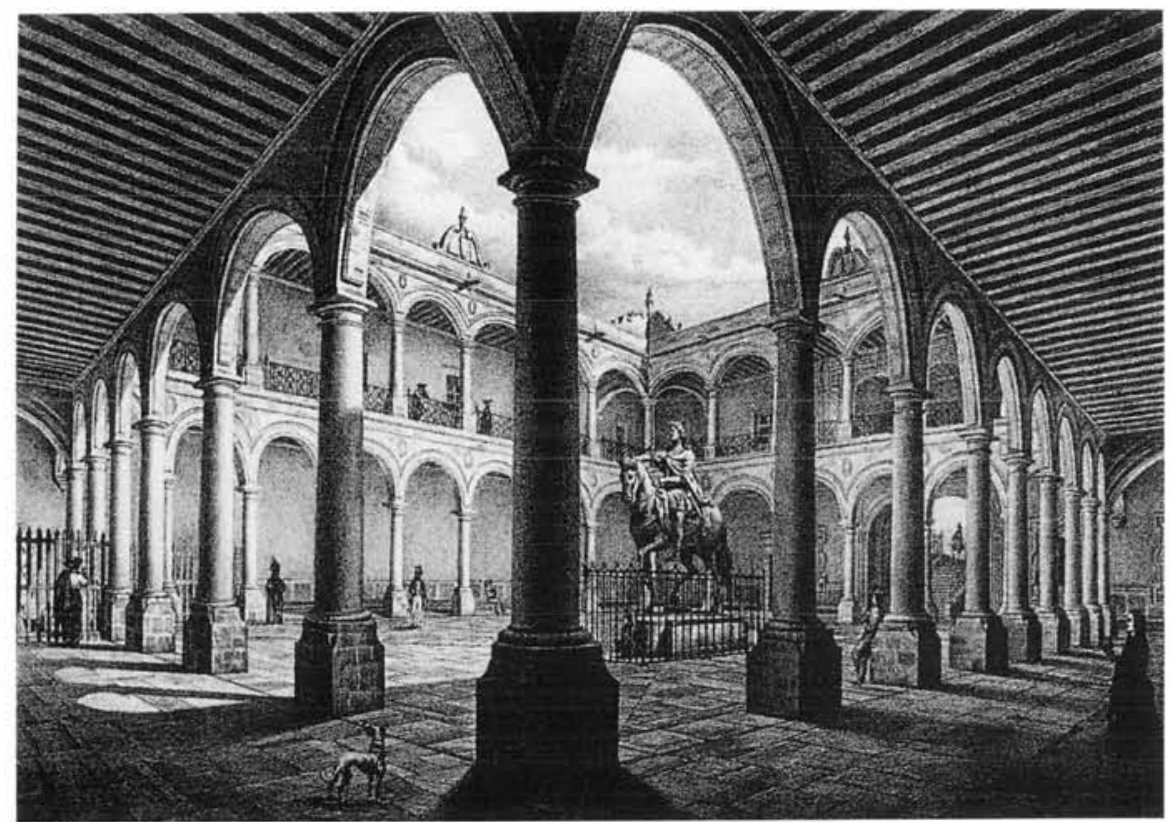

Figura I5. Pedro Gualdi, Interior de la universidad de México, 1841. Foto: R.L.M. 


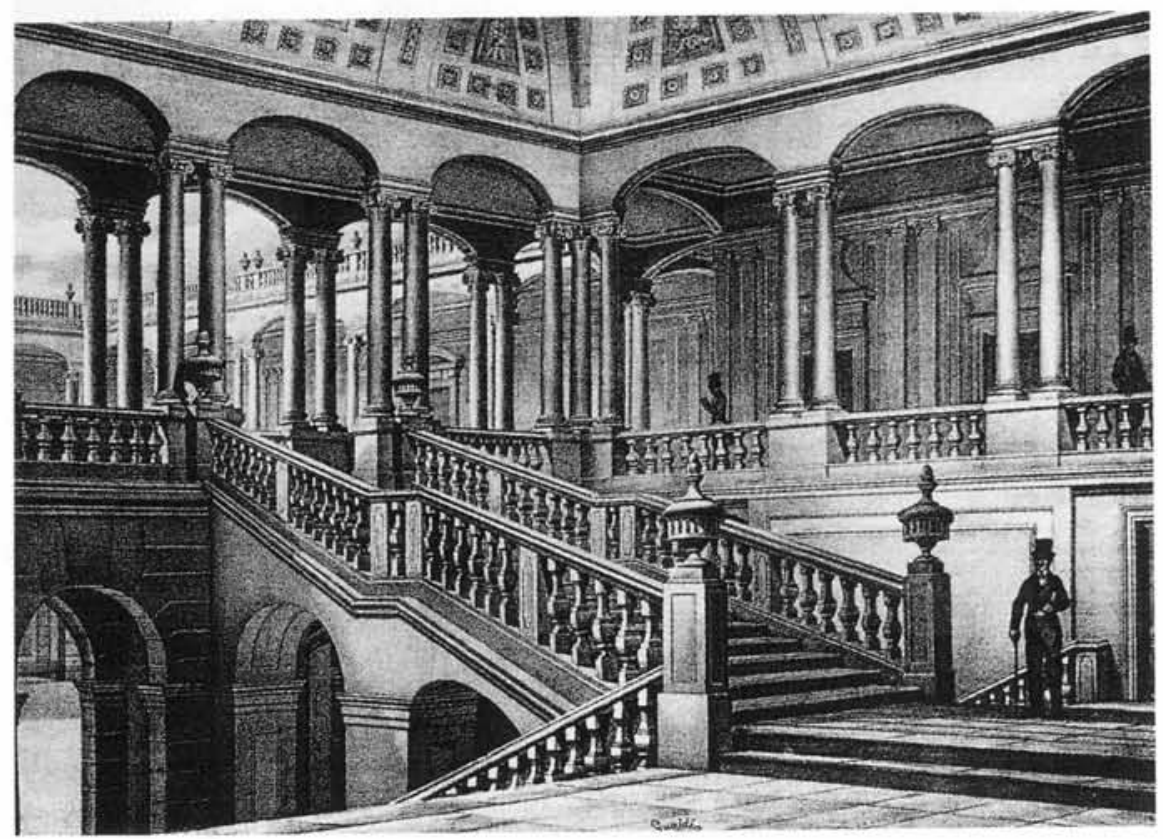

Figura 14. Pedro Gualdi, Interior del Colegio de Minería, I841. Foto: R.L.M.

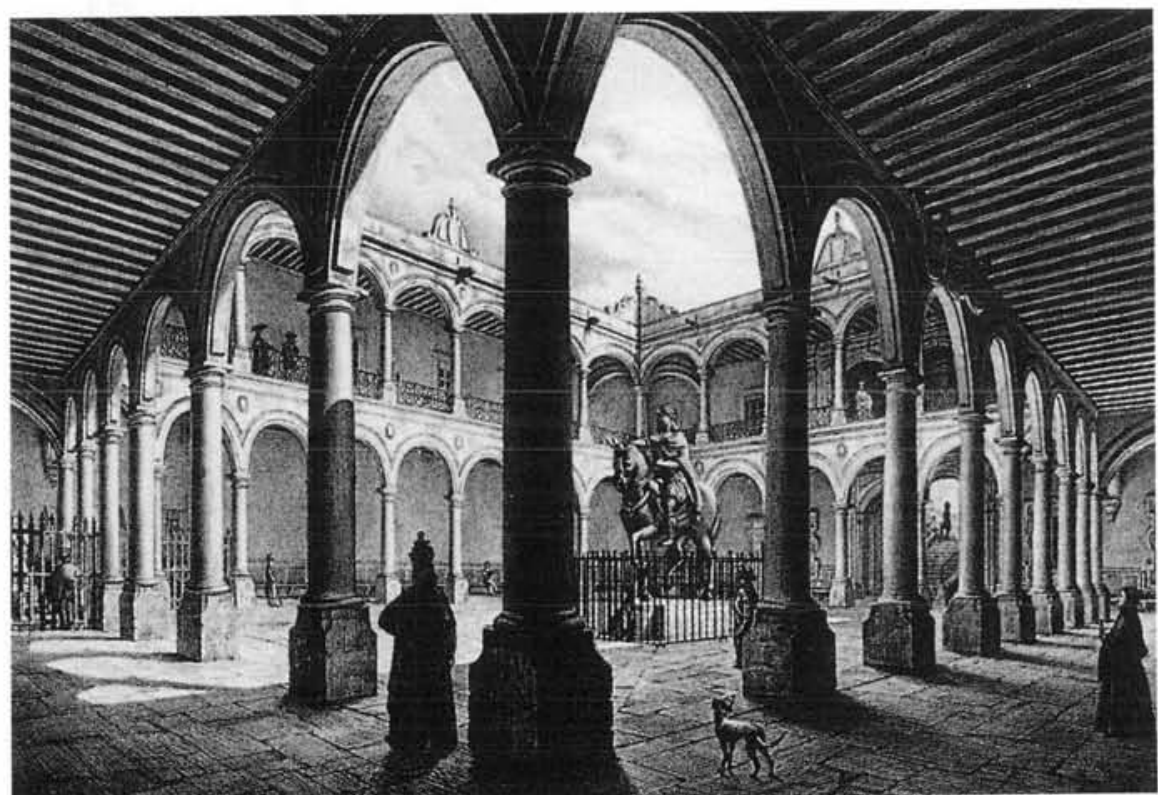

Figura 16. Pedro Gualdi, Interior de la universidad de México, 1841. Foto: R.L.M. 


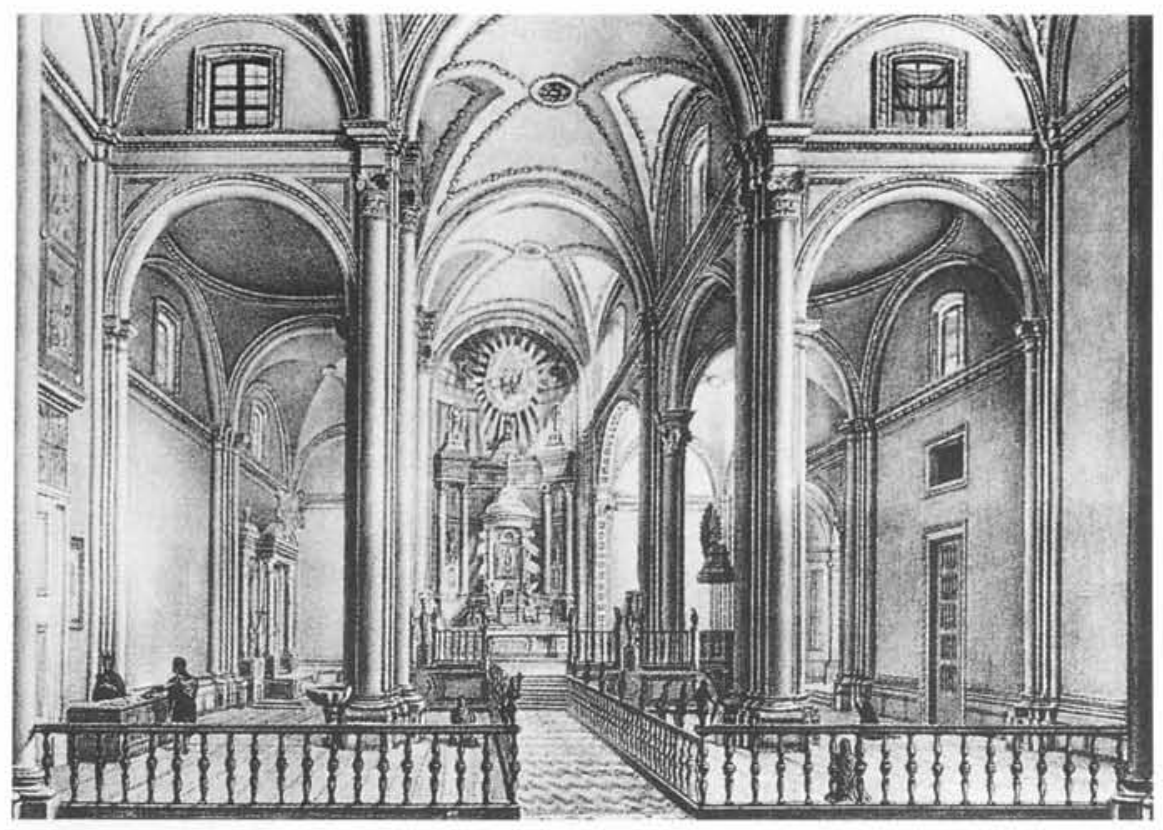

Figura 17. Pedro Gualdi, Interior del santuario de N.S. de Guadalupe, 184I. Foto: R.L.M.

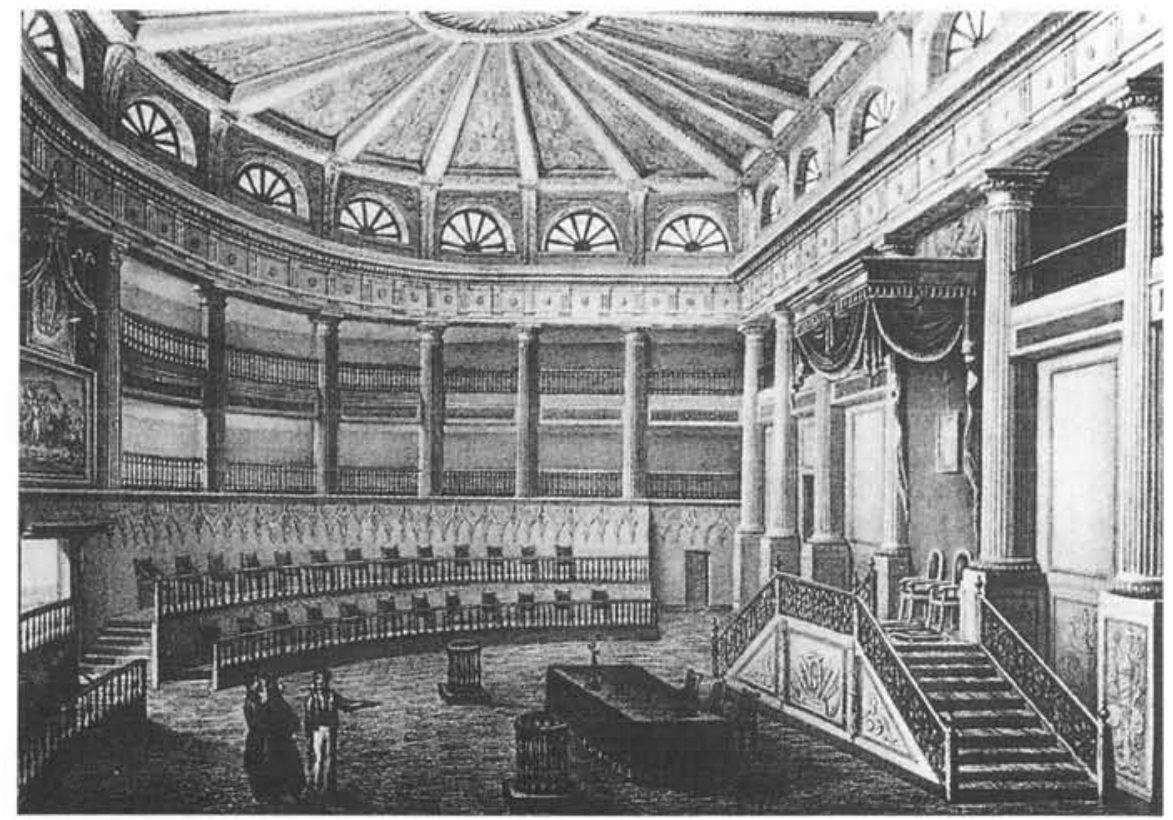

Figura 19. Pedro Gualdi, Cámara de los diputados, 1841. Foto: R.L.M. 


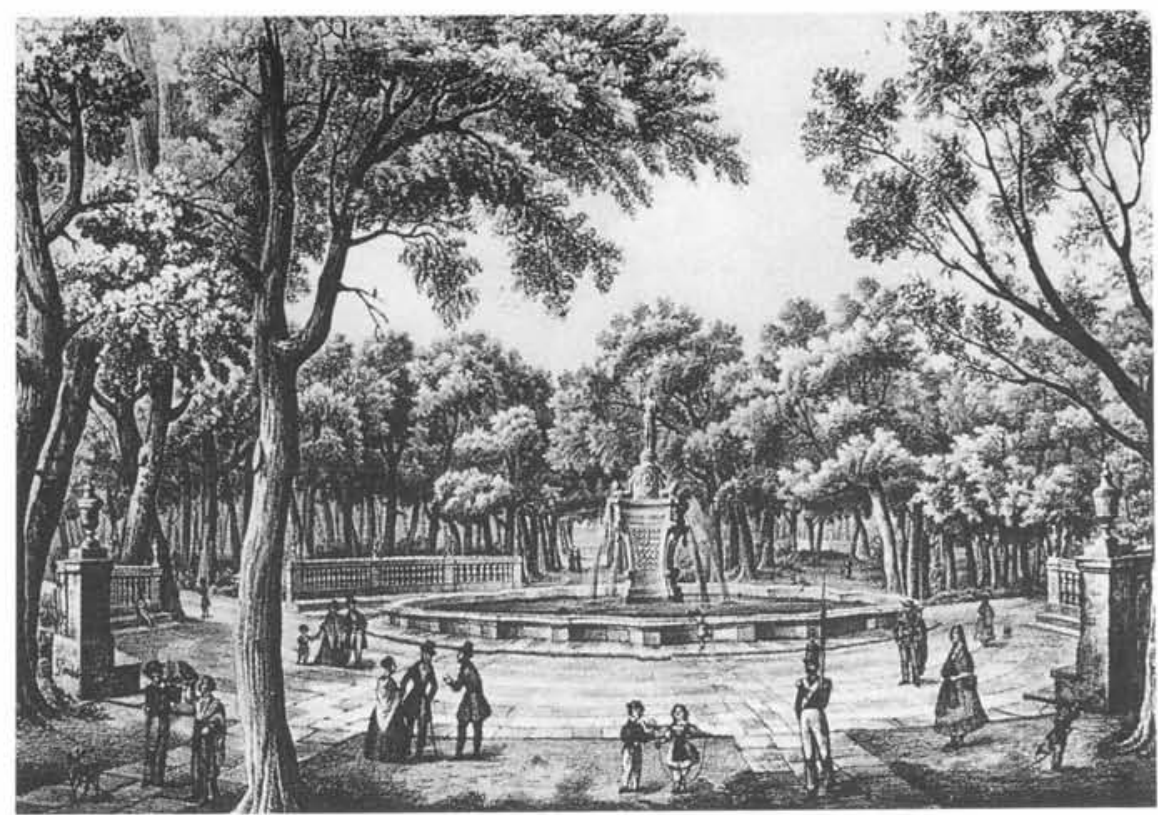

Figura 18. Pedro Gualdi, Alameda de México, 1841. Foto: R.L.M.

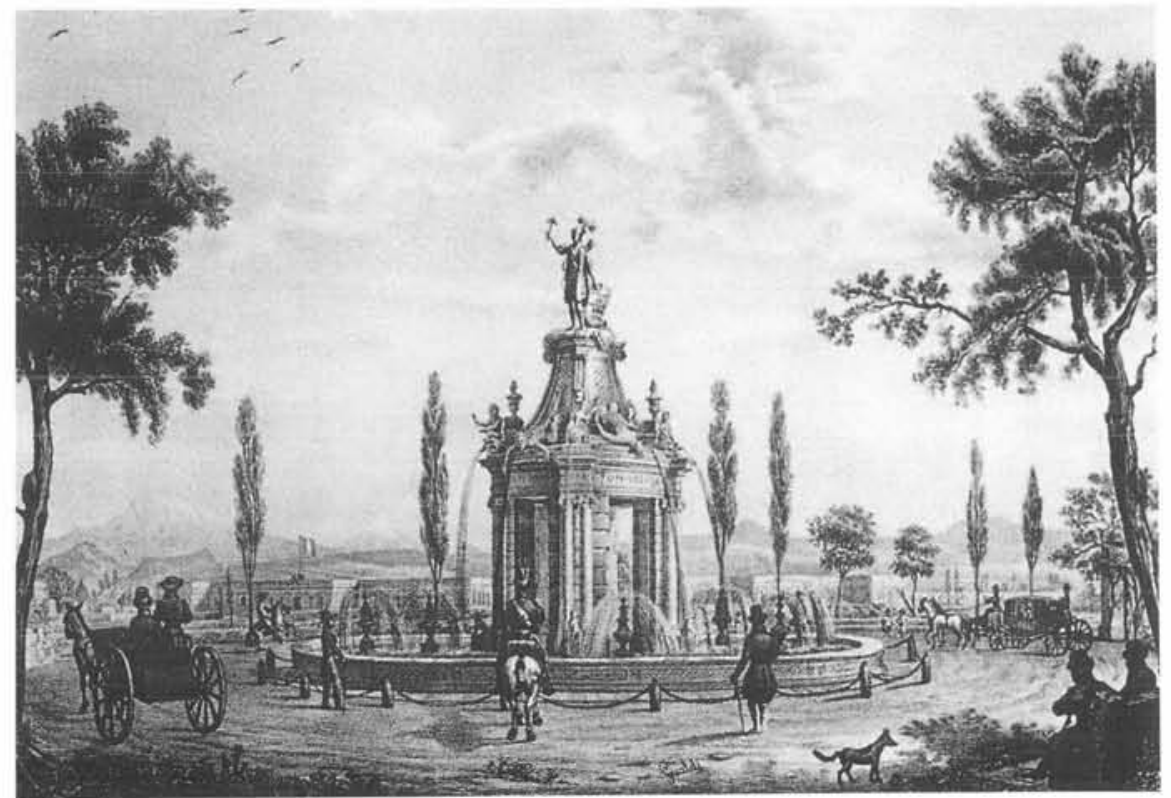

Figura 20. Pedro Gualdi, Paseo de la independencia, I841. Foto: R.L.M. 


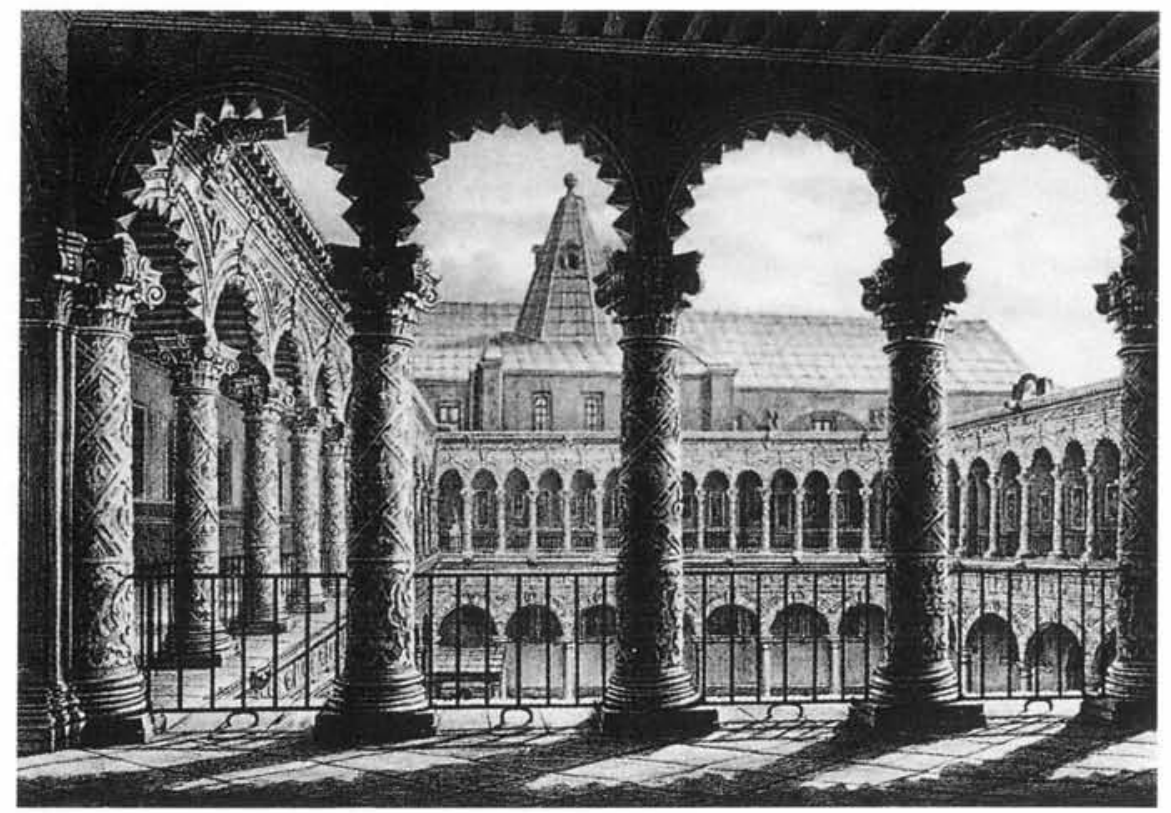

Figura 2I. Pedro Gualdi, Claustro del convento de Na. Sa. de la Merced, I84I. Foto: R.L.M.

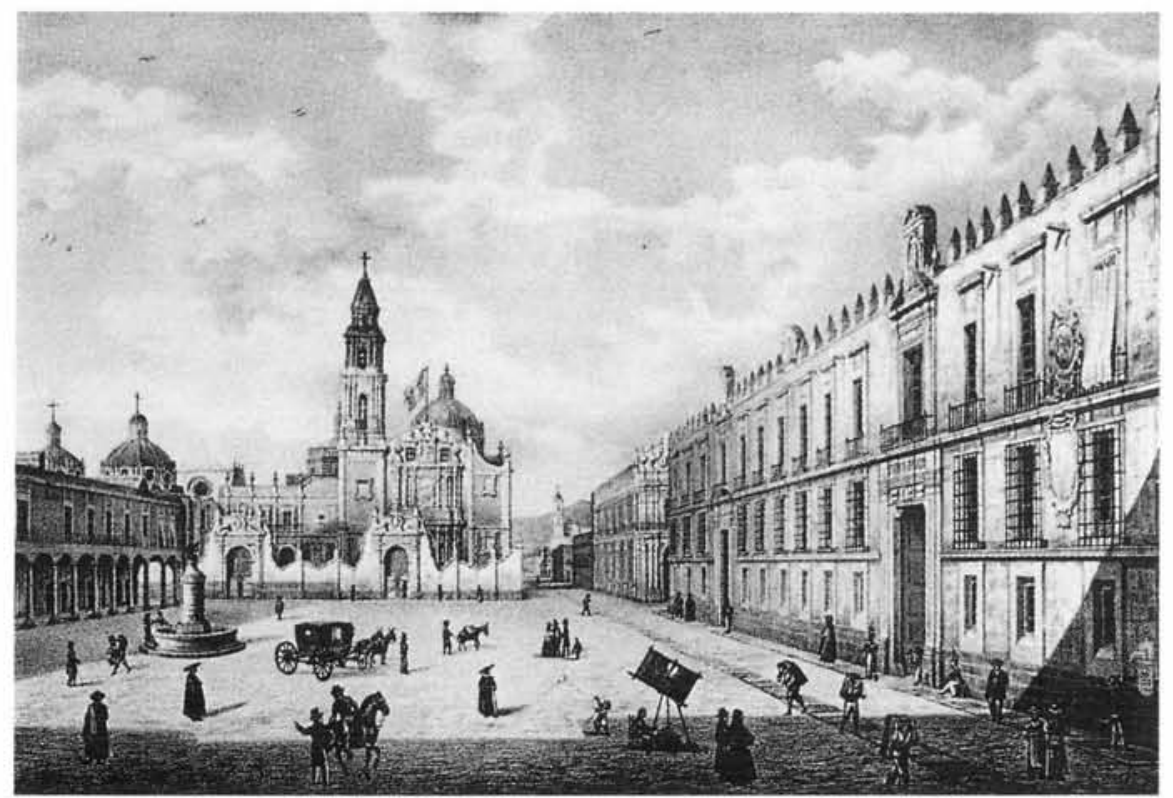

Figura 22. Pedro Gualdi, Plaza de Sto. Domingo y Aduana, I84I. Foto: R.L.M. 


\section{Cuadro I}

\section{Comparación de las estampas en las dos ediciones del álbum Monumentos de Méjico de Pedro Gualdi (Se copiaron cuidadosamente la ortografía y las anotaciones que aparecen abajo de las vistas)}

\section{Primera edición}

CATIEDRAL DE MÉJICO.

(La vista incluye una esquina del Parián.)

P. GUALDI, Lit y pintor

Firma Gualdi en la piedra.

INI ERIOR DE IA CAIEDRAL

(Vista del altar del Perdón)

Lito junto al Correo

P. GUALDT

Finma Gualdi en la piedra

SANTUARIO DE N S. DE GUADAIUPE.

(Vista exterior tomada desde el sureste)

Lito. I calle $S$ Francisco, $N^{\circ} 15$

P. GUALDI

Firma Gualdi en la piedra

Se vende en la casa del Autor Calle de Donceles $\mathrm{N}_{2}$

INIERIOR DEI SANTUARIO DE N.S. DE GUADAIUPE

Lito. Calle $S$ Francisco

GUAIDI Lit

P. GUALDI

Firma Gualdi $y$ I840 en la piedra.

COLEGIO DE MINERÍA.

(Vista exterior tomada desde el noreste.)

Lito junto al Correo

P. GUALDI.

Firma Gualdi y 1840 en la piedra

INIERIOR DEL COLEGIO DE MINERÍA

(Vista en el pario.)

Lito junto al Corteo

P. GUALDI.

Firma Gualdi en la piedra

\section{Segunda edición}

CAIEDRAI DE MÉJICO

(La vista incluye la calle del Empedradillo.)

Lito. I Calle $S$ Francisco. $N^{\circ}$ IS

Imptenta Lito. Massé y Decaen callejon $S^{a}$ Clara $N^{\circ} 8$

P. GUALDI, Lic

Firma Gualdi en la piedra

INIERIOR DE LA CAITEDRAI DE MÉJICO

(Vista del coro.)

Imp ${ }^{a}$ I ito de Masse y Decaen editores Callejon 5 Clara P. Gualdi, pintor y lit. $N^{\mathrm{O}} 8$

Firma Gualdi $y 1842$ en la piedra.

SANIUARIO DE N.S. DE GUADALUPE

(Vista exterior tomada desde el suroeste.)

Imprenta lito callejón S. Clara $\mathrm{N}^{-} 8$.

\section{AI AMEDA DE MÉJICO}

Lito de Masse y Decaen, editores callejon $S^{\mathrm{a}}$ Clara $\mathrm{N}^{\circ} 8$

Firmo Gualdi en la piedra.

COLEGIO DE MINERÍA.

(Vista exterior tomada desde el noroeste

Imp. Lito de Masse y Decaen callejon $S^{a}$ Clara $N^{\circ} 8$

Pedro Gualdi

Firma Gualdi en la piedra

INTERIOR DEI COLEGIO DE MINERÚA

(Vista de la escalinata)

Imp ${ }^{a}$ Lito de Masse y Decaen editores callejon $S^{a}$ Clara

Pedro Gualdi $N^{\circ} 8$

Firma Gualdi en la piedra

PIAZA DE SIO. DOMINGO Y ADUANA

Imprenta Lito. Masse y Decaen callejon $S^{a}$ Clara $N^{0} 8$.

P. GUALDI.

Firma Gualdi en la piedra

CIAUSIRO DEL CONVENIO DE NA. SA. DE LA MERCED.

Lito Masse y Decaen callejon $S^{a}$ Clara $N^{\circ} 8$

P. GUALDI,

Fima Gualdi en la piedra

\section{CASA MUNICIPAI}

(Sin carroza)

Ĺto. Junto al Correo

P. GUALLíl.

Finma Gualdi on la piedra

INIERIOR DE LA UNTVERSIDAD DE MÉXICO

(Personaje al centro, perio hacia la derecha)

Lito. frente al Correo $\mathrm{N}^{-}$,

P. GUALDI. Iito.

Firma Gualdi en la piedra
CASA MUNICIPAL.

(Con carroza de caballos.)

Imp lito. de Masse y Decaen, Editores callejon S Clara

Pedro gualdi. No 8 .

INIERIOR DE LA UNIVERSIDAD DE MÉXICO

(Sin personaje al centro, perro hacia la izquierda..)

Imprenta Lito de Masse y Decaen, editores callejon

Pedro Gualdi, 5 Clara $\mathrm{N}^{0} \mathrm{~B}$

Fima Gualdi en la piedna

PASEO DE LA INDEPENDENCIA

Imp ta Lito de Masse y Decaen. Callejon S Clara $N^{\circ} 8$

P. GUALDI

Firma Gualdi en la piedra.

CAMARA DE IOS DIPUTADOS.

Imp ${ }^{t}$ Lito de Masse $y$ Decaen Callejon $S^{a}$ Clara $N^{\circ} 8$

P. GUALDI.

Firma Gualdi en la piedra 


\section{Cuadro II}

Datos sobre ejemplares del álbum Monumentos de Méjico de Pedro Gualdi, en ediciones originales, que se pudieron localizar:

Colección privada "C"

México, DF

Colección privada " $\mathrm{M}$ "

México, D.F

INAH (sirvió de original a la edición facsimilar Monumentos arquitectónicos y perspectivas de la ciudad de México, r84ır, Chavarri y Arce editores,

México I966).

Instituto de Investigaciones

Estéticas, UNAM

Universidad Nacional Autónoma de México

\section{Colección Privada "M"}

México, DF

Ejemplar " $\mathrm{X}$ "

(No se localizó).

The Watkinson Libraty Trinity College,

\section{Hartford, $\mathrm{CI}_{\text {. }}$}

The Sutro Library, San Francisco, CA.

Virginia Theological Seminary

Alexandra, VA
Portada Ia, ed. Contiene todas las vistas de la ra edición y las 8 que son diferentes en la za. edición.

Portada 1a, ed. Contiene las Iz estampas de la ra edición.

Portada za ed. Fl facsimilat cuenta con las I láminas y además tiene cuatro panorámicas y una vista más que falta en el ejemplar original.

Portada 2a, ed. Contiene las d2 estampas de la $2 a$ edición.

Portada 2a. ed. Además de la portada cuenta con ro vistas del album, las cuatro panorámicas de la ciudad con sus hojas de explicaciones, Teatro Nuevo (Santa Ana), Capilla de Sa. Teresa después del borroroso temblor del 7 de abril de 1845 en México, (Lit Cumplido), Interior del Teatro Nacional No 4, Colegio Militar de Chapultepec No. 2 (las últimas dos de Lito Murguía Fx Recuerdos de México) y muchas otras litografías (incluyendo unas del Despertador Mexicano) y mapas sacados de obras varias.

Portada 2a. ed. Contiene las I2 estampas de la za edición.

Portada 2a. ed. Sirvió de original para la edición facsimilar que publicó Fomento Cultural Banamex en 1982.

Portada 2a. ed. "Santuario de N.S de Guadalupe" es de Callejón de $S$. Clara, las demás de Masse y Decaen.

Portada 2a. ed. Además de la portada solo tenen 3 vistas:

Portada 2a. ed. Mineria, Universidad y N.Sra de Guadalupe, todas impresas por Masse y Decaen.

Jodas las Impresiones son de Masse y Decaen

No se encontraton ejemplares de ediciones antiguas del álbum de Gualdi en la Biblioteca de México, ni en las biblioteca del Instituto Mora, del Centro de Estudios de Histotia de México Condumex, del Museo Franz Mayer, ni en la British Libraty y numerosas bibliotecas de los Estados Unidos de América. 